\title{
Sustainable mining now: turning ideas and ideals into reality
}

\author{
R.M. Abbott Abbott Strategies, Canada
}

G.T. McKenna BGC Engineering Inc., Canada

\begin{abstract}
Most mining companies are committed to sustainability. Many are on a path towards corporate change that is plotted over decades and held largely separate from mine operations and corporate or line decisionmaking. Efforts and publications to date they have not confronted the urgency of the sustainability challenge and have failed to provide clear, tangible advice on 'how to turn ideas and ideals into reality.'

This paper redefines sustainable mining as the emergent outcome of seven elements: engaging communities and earning trust; exercising planning, decision making, and design with flair; executing promises operationally; empowering employees; efficiently managing resources; exceeding shareholder expectations; and enhancing the environment. 'Sustainable mining now' offers a three year blueprint for corporate executives and mine managers to implement meaningful sustainable mining such that it becomes the new normal just as safety and environmental protection have become the new normal at most mines.

Mining sustainably starts during exploration, continues through operation, and many of the results are most evident during reclamation and mine closure after mining ceases and the land is readied for new uses. Building reclaimed watersheds and landscapes collaboratively with the new users is central to this new way of doing business, achieving 'successful reclamation' together. Examples of mines achieving one or more of the seven elements, and tools for collaboration and landform design are becoming available to aid interested mines, their shareholders, and stakeholders. Sustainable mining as we define it is not 'nice to have'; it is smart business.
\end{abstract}

\section{$1 \quad$ Introduction and context}

It is often said that 'if it's not grown, it's mined', a telling reference to the fact that human society is more dependent than many might like to think on mining. Indeed, virtually every electronic and mechanical device in a home or office; school or hospital; plane, train or automobile would be difficult or impossible to create without the products of mining. And so it is that we have a very particular interest in contributing to a dialogue about the evolution of this industry - an industry that continues to increase its rate of resource extraction - such that we had better reconcile the need for the products of mining with the need for natural capital assets and the flow of life-sustaining ecosystem services provided by nature. This paper is intended to spark real dialogue within the industry globally about how to think about, and achieve the seemingly impossible: sustainable mining - mining that creates financial and social wealth and wellbeing in a way that does not undermine or otherwise damage the aesthetic and productive capacity of natural capital for present and future generations.

We are not the first to call attention to this need within the global mining industry, but we do believe that previous efforts have been too narrowly defined or scoped, or too 'polite'; they have not confronted the urgency of the sustainability challenge and have failed to provide clear, tangible advice on 'how to turn ideas and ideals into reality'. This paper is an attempt to address these gaps very directly. Most large mines express commitments to sustainability and there are numerous reports and initiatives that speak to a 'transition' to sustainability at some point in the future. If such a transition is underway, it is our belief that the pace is much too slow, lagging behind other industries - and the rapidly accumulating scientific evidence of the need for a 'step change' in mining performance. Moreover, the way in which sustainability has been framed within the mining industry is as 'nice to have' that has little to do with the business. In our 
view, sustainability can be - should be - the next evolutionary progression within mining; it should drive future business performance and come to be seen as the standard by which mining companies are measured - by shareholders as well as other stakeholders. Put simply, we envision a future where the most viable business strategy for a mining company will be what we call here a sustainability strategy.

With this in mind, we asked ourselves - if the mining industry is really committed to transitioning to sustainable mining over the next few decades, say by the year 2040, what would things look like in 2040 ? What would be the face of sustainable mining at that time? We then asked ourselves why an individual mining company or mine could not act much faster - why wait?

Most mining companies have public, stated commitments to sustainability. Most produce an annual sustainability report. But for most, this is a repackaging of existing social and environmental activities, separate for the most part from the operations, and separate from corporate or line decision making. Said simply, these commitments are reports are well-intentioned, but they are proportionally more public relations and communications devices than something of real substance that defines overall corporate performance.

What is lacking is a clear and easy-to-understand roadmap to achieve sustainable mining now - a blueprint for corporate executives and mine managers to implement meaningful sustainable mining such that it becomes the new normal - the new business as usual. A template, of sorts, is the industry's experience with safety and the efforts that have been made globally to weave a real culture of safety into day-to-day operations. So it needs to be with sustainability.

Sustainable mining is needed to ensure future generations on earth enjoy the same opportunities that we were bequeathed from the generation that came before us, but it is about more than that. It is also about building companies that people are proud of; companies that endure; companies that provide good financial returns to shareholders and satisfaction for management; companies that are seen to be pillars of the communities in which they operate - and in the communities of interest that monitor and track these companies. And one of the enduring outcomes is the creation of safe and useful closure landscapes, a major focus of this conference. In short, sustainable mining as we define it is not some soft and - mushy 'nice to have'; it is smart business.

\section{The seven elements of sustainable mining}

It is our view that sustainable mining is the emergent outcome of doing the following seven things as excellently as possible:

- Engaging communities and earning trust.

- Exercising planning, decision making, and design with flair.

- Executing promises operationally.

- Empowering employees.

- Efficiently managing resources.

- Exceeding shareholder expectations.

- Enhancing the environment.

\subsection{Engaging communities and earning trust}

For too long the practice in mining has been to either ignore communities and communities of interest, or to push information at these groups, often under the masthead of 'consultation' or 'community investment'. The fact is, in a world of rapidly diminishing natural capital, and rising consumption, all extractive resource companies must learn that their license to operate and license to grow is dependent on meaningfully identifying and engaging communities and earning their trust. This should start well before 
mine design decisions have been made, and continue through the life of the mine to closure and reclamation.

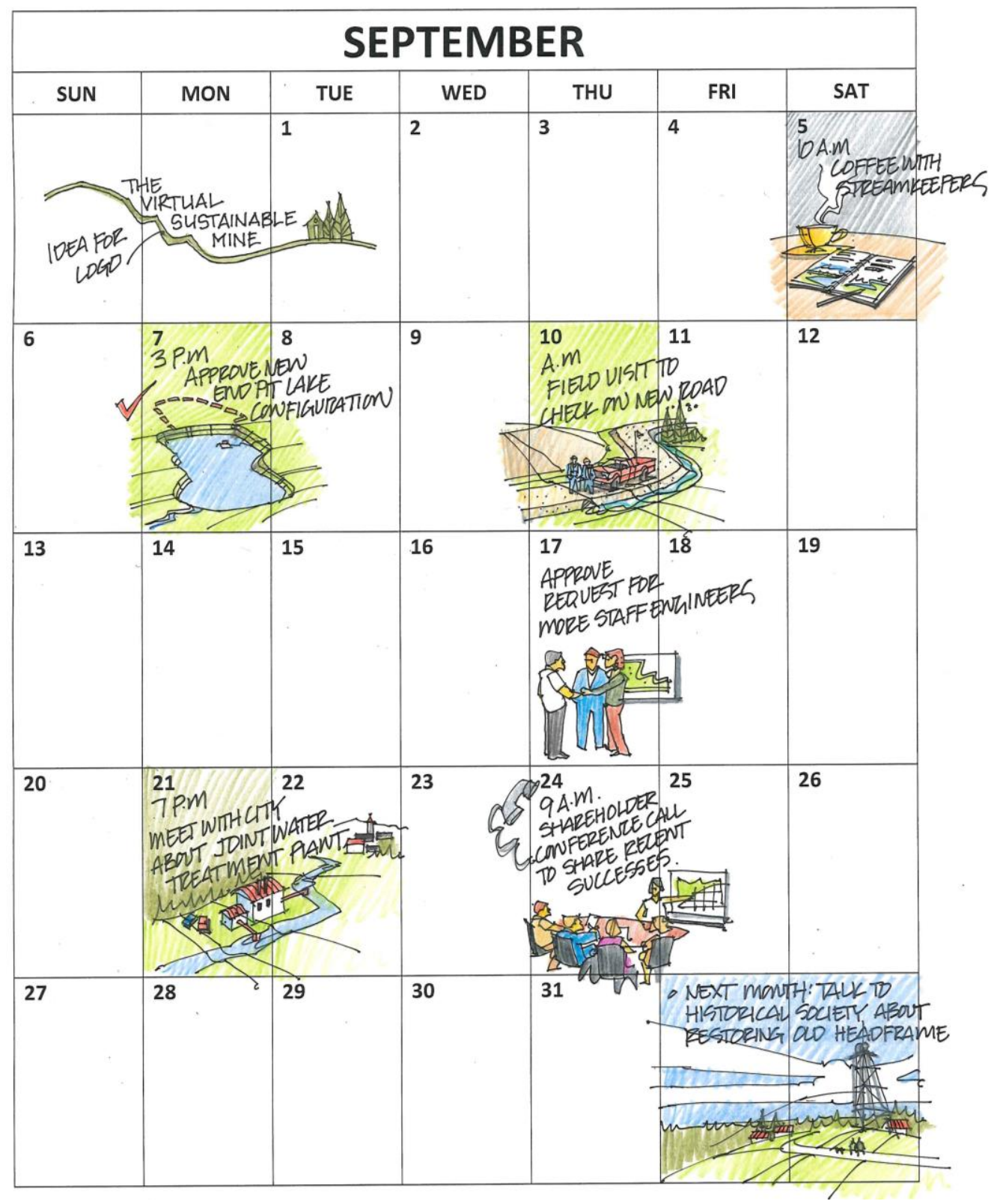

\section{Figure 1 A committed mine manager's monthly planner}

The work to engage communities - and communities of interest - and earn their trust should begin before exploration and continue well after mine closure. This means that the company should have a mindset of forging lasting community connections and being outward focused as well as inward focused. The norm, in our experience, is to be largely inward focused and to 'consult' or 'communicate' with external audiences, usually regulators and a small number of non-government organisations (NGOs) only when absolutely necessary. Our call, therefore, is for a dramatic change in strategy, a change in the ways in which the company is, and is seen to be by the community. To get there, the sustainable mining company needs to do the following:

1. Build a stakeholder map that includes its supply chain and value chain; the local community; local government agencies (municipal, regional, provincial/state, federal), NGOs, First Nations, and communities of interest. It is important to look beyond the local community, where many individuals will be employees of the mine and, other things being equal, supportive of mining 
activity, to communities of interest, which may include government agencies, academics, bloggers, writers, non-government organisations and other stakeholders far removed from the local community.

2. The stakeholder map should be divided into high impact/high influence; high impact/low influence; high influence/low impact; and low influence/low impact. While it is important to track all stakeholders, and update the map at least annually, emphasis should be given to high impact/high influence stakeholders.

3. With the stakeholder map completed, the next step is to begin having strategic conversations with the high impact/high influence stakeholders to alert them to the company's exploration and mine development aspirations, and to listen to any comments or concerns that the stakeholder might have. It must be stressed that this is not a one-off consultation exercise; it is the beginning of a process to build relationship, to build social or trust capital, and to demonstrate a willingness beyond tokenism to involve community members in decisions that will affect them.

4. A key reason why we believe it is critical that the engagement process begins prior to or concurrent with exploration is that it will take time - at least six months to a year - to establish rapport and trust. And this must be achieved before meaningful dialogue can take place on mine design and planning. The focus of the initial engagement effort therefore, is not pushing out information, but demonstrating a willingness to listen, a willingness to show empathy for those who are concerned about mining activity, and a willingness to collaborate on a common vision of how mining activity could take place.

5. Engagement is about two-way dialogue. The company should explain what it is thinking of doing, and why, but emphasise, especially in the early days of engagement, that this is only one of several potential visions. The company should solicit input. The company should ask its high impact/high influence stakeholders what they think of the proposed plan, what concerns they might have, what ideas they have to improve it, and how they would like to be involved in the longer term.

Engaging communities and earning trust is fundamentally about redefining how mining companies do things - it is the first step in writing a completely different chapter in the company's history.

Ultimately, engaging communities should be viewed as nothing less than a sincere and genuine desire to listen, to learn, and to walk forward together.

\subsection{Exercising planning, decision making, and design with flair}

In a truly sustainable mining operation, there is one overarching mine plan, slices of which are communicated several ways - the development plan, the mine (operations) plan, and the closure plan. They are inexorably linked from beginning to end, and while they change with time, they remain true to the vision and commitments. The plan is based on decisions made jointly with regulators and other stakeholders and the activities on the ground are based on formal, well-documented designs. The mine extracts the resource for society, and builds new, useful watersheds in new landscapes for the people, flora and fauna of the region. All planning and design decisions are made with profitability, social licence, and environmental enhancement as key pillars. Enough data is gathered early enough that while major changes in the plan are rare, they are anticipated and planned for, and most of the focus is given to continuous improvement - reacting to local conditions, local opportunities and ingenuity, new ideas and technology, and the changing fabric of society and stakeholders. The planning, decision making, and design beings with exploration, and includes all of the activities needed to take the mine from development, through operation, into closure, decommissioning, and perpetual care. Good planning - planning with flair reduces stress and uncertainty, and provides confidence to all interested parties that the resource will be extracted sustainably. 
A mine is an unusual business entity in that it has a finite life and goes through predictable stages from exploration, to development, operations, closure, and ultimately abandonment. The resources a mine produces are often consumed right away; the jobs, though long-lived, are ultimately temporary. The mine, however, leaves behind a legacy of economic benefit (to the workers and the users of the mined commodity), training, infrastructure, and a reclaimed landscape. People who see sustainable mining as an oxymoron do not look past the depleted ore body.

Guiding a mine throughout its life cycle is the mine planner - the glue that holds the mine together, documenting what has been achieved, and planning for what will take place. Mine planners evaluate the geologic drilling to determine how best to mine the ore, and whether the mine is likely to be economically viable. Most prospective mines are not viable, and do not move beyond the exploration phase. Even one in four of those that go through development and into production fail in the first few years. Exploration and mine development is very much for optimists who focus on the art of the possible - what can be achieved.

Before invasive exploration can begin, an exploration permit is needed - for building access roads, drilling, and camps. Previously unregulated, and leaving behind a land scarred with washed out roads, contaminated drill pads, and geology cores strewn about the landscape, exploration is now highly regulated in most jurisdictions with a focus on protecting the environment. The need is acute for areas with sensitive wildlife, the potential for flowing boreholes to contaminate streams or other water bodies, or acid rock drainage escaping from exploration adits or large test pits. The same seven elements of sustainable mining are applicable to exploration and if well planned, can be easily implemented. The trick, if we might call it that is to approach exploration, planning and design with flair.

Mine planning, decision-making, and design permeate and guide all stages of exploration, development, operations, and closure. In particular, long-range mine planners play a central role in leading, coordinating, and performing these tasks. A critical element of successful sustainable mining is to have good planners, well trained, empowered, and with vision. The long-range mine planning team must be - and be seen to be - a central focus if sustainable mining is to be achieved.

Geologists, working towards defining an ore body that can be mined profitably, often drive the exploration phase. While it has become recognised that poor planning and execution of the exploration phase can leave scars on the landscape, affect wildlife, and send pollution downstream, we now recognise that good planning and execution can enhance the environment - providing access to inaccessible areas, providing good mapping and topography, demonstrating a commitment to sustainability to local stakeholders and regulators, and balancing the need to minimise the costs of exploration with leaving a positive legacy even if the mine does not go ahead.

Before development can begin in earnest, a mine needs corporate approval, a regulatory permit, which requires a mine plan, a reclamation and closure plan, stakeholder buy-in, and an environmental impact assessment. All of these items hinge on good planning, good decision making, and good design. Good management and long-range planning are central to both.

A good mine plan begins with clear and comprehensive delineation of the ore body. Geologists and miners in general are proud of a tradition of 'just in time drilling' - drilling that is staged throughout the life of a mine, using the cash flow to fund expensive drilling that usually allows expansion of the known ore body and an increase in the mine life. But the new drilling often results in a major change to pit limits, the need for new waste rock dumps, enlarged tailings facilities, and more infrastructure. While this is generally positive, it often requires a major change to the closure plan, and often severely compromises that plan heightening the risks to natural, social and cultural environments, and raising the distinct possibility of longterm landscape performance. For example, the mine may have been optimised to allow surface water drainage to exit the mine area in a certain direction, but with a change to the plan, it may need to be rerouted less optimally to allow for a new pit. Under a commitment to sustainable mining, there would be enough drilling done in advance of mining (or in the earliest stages of mining) such that there are no surprises; the extent of the ore bodies (and often nearly as important, the extent of the barren zones) are well enough defined that there are no major changes to the closure plan required. 
Economics, protecting the environment, gaining stakeholder support and safety are the central focus of current mine permitting. Sustainable mining builds on these activities, and adds sustainability as a new and explicit focus. Planners and decision makers must embrace sustainability as a central tenant. Planners will look for opportunities to avoid disturbing areas that will be difficult to reclaim, minimise infrastructure sprawl by creating corridors and keeping facilities close, leaving room for expansion. Stakeholder concerns and preferences will be well catalogued and kept front and centre in design, with regular feedback on how these concerns are being addressed. Each time economics are calculated or decisions made, sustainability will be part of the conversation.

Long-range closure plans and mine plans are typically updated every five years; they often take a dedicated team about a year to produce. Strong linkage between these two planning efforts is critical to overall mine success and an area ripe for performance improvement - explicit movement toward sustainable mining. Again, the long-range mine planners must play a central role.

\subsection{Executing promises operationally}

It is the activities that the mine undertakes that demonstrate its commitments and it is these same activities that distinguish one mining company from another. These activities include everything the company does to translate its vision and mission into activities that ultimately generate economic value to society and shareholders. Promises are the commitments made to regulators and other stakeholders. They should be logged, tracked, publically available, and reviewed regularly. They should be amended as a group as times and preferences change. They should embody the underlying principles and goals behind all mining activities. Promises should be meaningful, clear to all parties, reasonable, achievable, and focussed on things that matter - things that contribute to sustainability for the company and its stakeholders, as well as the natural, social, economic and cultural environments. Plans and activities should be designed to meet these promises, and both the company and its stakeholders should take pride in these results together.

\subsection{Empowering employees}

All company success, in any industry, is due to employee effort. While ore reserves are fundamentally important to the success of a mining company - they are the 'hard assets' that are ultimately sold into the market, it is the decisions made by employees about how to most effectively and efficiently extract the reserves that can tip the balance from good to great, or acceptable to unacceptable. These 'soft assets' are the source of real value in a mining company and they need to be empowered if the company is to achieve sustainability as we define it. A truly sustainable mining company - a company that aspires to greatness should strive to create the conditions in which employees at all levels believe they can bring their 'full person' to their job; conditions in which every employee feels truly invested in the fate of the company.

For a long time, it was thought that success in business was a function of a charismatic CEO, or one or two smart people, the 'idea guys', who inevitably figured out how to tackle a particular problem. Make no mistake, having smart people is great, perhaps even essential, but in the absence of truly spirited teamwork, a company will always fall short of what it might otherwise have achieved. What if one of those smart people leaves the organisation or is hit by the proverbial bus? Who will step in to fill the void? For enduring success, companies must understand that their employees - all employees - are critically important stakeholders, the custodians of both the company's legacy and its future potential, and the basis for the structures, processes, and attitudes that distinguish one company from another. These employees must be encouraged and rewarded to relinquish individual goals in service of the larger company goal. They must become a team in the truest and broadest sense of the word. To get there, we suggest the following:

- Actively engage employees in a conversation at the beginning of the journey to sustainability - let them know that this is a new aspiration for the overall business, not simply a new objective for the environmental department, and that their ideas, hopes, and concerns are genuinely wanted.

- Listen to what employees have to say. 
- Identify the ways in which employees can best support the sustainability objective - what specific activities are they especially excited about? What changes in responsibility and authority would better enable employees to achieve sustainability objectives?

- Map the critical sustainability requirements into specific job functions and identify specific training and educational needs to enable those job functions to meet those requirements.

- Embed sustainability requirements into personal performance reviews such that every employee at all levels of the company has a stake in the achievement of those requirements.

- Identify changes in work process - flexible hours, telecommuting potential, etc. - that would better enable employees to achieve work-life balance.

- Be mindful of the explicit or implicit cultural or organisational narrative that exists within the company - this will influence how fast you can move, where you can best exert influence, and so on.

- Be mindful of the cultural ethos in the community (or communities) where the company operates. Has the company created, or is it creating a legacy of violating cultural norms or behaviours?

Truly empowered employees are the most important strategic assets for a company - on sustainability and other matters. The ability to engage and empower employees is also a powerful way of both attracting top talent, and retaining key employees once they are inside the company. Given the very visible role that employees play as ambassadors or potential ambassadors for the company in the community, empowerment can assist in positioning the company not simply as an employer, but as a pillar of the community - a trusted community member whose opinion is sought on the key issues, challenges and opportunities facing the community.

\subsection{Efficiently managing resources}

In 1969, Ian McHarg published Design with Nature, arguably the most influential book in landscape architecture and design in the 20th century, and a book that introduced many ideas that would be popularised 30 years later under the biomimicry and green chemistry labels. He begins with the words: "The world is a glorious bounty". What he means is that the answers to our design (and other) questions are inevitably to be found in nature. He says:

In the quest for survival, success and fulfilment, the ecological view offers and invaluable insight. It shows the way for [humanity to be] ...steward, enhancing the creative fit of man-environment, realizing design with nature.

This is an important touchstone. Waste is, after all, a human construct: in nature there is no waste.

If we shift our focus from attacking specific elements of the waste stream to looking higher up on the face of the metaphorical pyramid, we confront another, deeper definition of waste, 'any useless or profitless activity'. This definition opens up several expansive possibilities, possibilities that draw inspiration from nature, possibilities that speak to changes in entire industrial or organisational ecosystems. This definition, for example, has spurred the lean manufacturing model.

Lean is fundamentally about working with less waste, but waste is here defined in broader terms than simply materials. By adopting a lean philosophy manufacturers review all business practices in an effort to reduce all forms of waste - time, people, materials of all stripes, and so on. What's more, this review process never stops; the underlying philosophy is that no matter how good a process or practice, it can always be improved.

And so it is that we call on all mining companies worldwide to manage all resources (land, water, air, people, institutions, infrastructure, and so on) to maximise efficiency. Do not consume if possible; reduce consumption that does occur; recycle and reuse, and provide good long-term jobs for employees, good 
short-term jobs for contractors and specialists. Share assets with neighbouring mines, industries, towns, and civic infrastructure.

\subsection{Exceeding shareholder and stakeholder expectations}

While it is true that Milton Friedman, the Nobel prize-winning economist, once said that the only responsibility of a business was to make a return for the shareholder, he also added, "as long as it remains within the rules of the game". And so it is that companies must have a strategic line of sight that includes the shareholder, to be sure, but also includes a wider range of stakeholders who have the ability to support or deny a company's license to operate and license to grow. The fact is, the 'rules of the game' have changed in recent years and no company can operate in a truly sustainable manner by focusing solely on the shareholder - all stakeholder expectations should be considered.

To meet the above aspiration, we recommend the following activities.

\subsubsection{Embrace change and initiate opportunity}

Strategic positions in any industry can be overthrown very quickly. It is therefore important that individual companies continually tune their strategic radar to identify potential threats and opportunities. In particular, companies must be alert to strategic discontinuities or 'disruptive change', change that lies outside the normal sphere or operating context. Examples include the global movement toward a less carbon intensive economy; the loss of environmental and cultural diversity throughout the world especially in countries that are home to significant mining operations; the phenomenon of key stakeholders raising their expectations of business generally and individual companies in particular, and technology changing the way in which people live, work and play - with consequent impact on existing commodities and the products that are made from them. In the face of these seismic shifts, companies must resist the temptation to fight back; rather, they must embrace the change and actively look for the new opportunities that change inevitably brings.

\subsubsection{Cultivate a passion for growth and development}

Truly great companies, what we would call sustainable companies, have a passion for development that fuels their financial, social, environmental and cultural success. They are not content to simply do the same things they have always done - with perhaps more energy and enthusiasm than their competitors. They foster an organisational ethos that encourages new ways of thinking, and is open to new ideas, regardless of whether those ideas originated with a mine manager, plant foreman, or dozer operator. The point is to think and do things differently, and better than they have been done before. In this way, the company is developing internal capacities that make it resilient in the face of change and that reflects and meets the requirements of both shareholders and stakeholders.

\subsubsection{Encourage the courage to innovate}

While the expression 'necessity is the mother of invention' has become part of our collective consciousness, it inadvertently narrows the strategic field of vision that we believe great companies must have. Invention, or more properly, innovation, is something that should be a reflexive, ongoing characteristic. You cannot wait for period of necessity - as the great economist Joseph Schumpeter might have put it, if you wait for necessity the competitive winds of creative destruction will wipe your company off the map. And so we must talk about the courage to innovate, to foster a an organisational culture of innovation that takes a percentage of each year's revenue and reinvests that in a true innovation agenda that redefines your company and its position relative to peers (and emerging peers). We are not talking about tweaking the existing business; we are talking about deep conversation that considers the ways in which technology might shape the strategic positions available to your company and the points-of-view your company has about its long-term growth trajectory. These are the kinds of conversations that some might see an academic or abstract, but they are absolutely core to the future positioning of mining companies worldwide. 


\subsection{Enhancing the environment}

Not so long, the conventional wisdom held that it was okay to 'tame' the land, clearing trees and brush, culling animals that might compete with us, making waterways more navigable, and generally making the environment more 'beautiful' and or suited to our desired ways of life. One of the more extreme examples of this hubris was an earnest plan to 'enhance' Niagara Falls to make it more beautiful (Cronon, 1995).

We now recognise that we can do better - we must do better. Nowhere is this more visible in a mining context than in the art and science of closure and reclamation. All active mines carry out reclamation but few carry out successful reclamation - reclamation that supports the mine's operational and corporate objectives, allows certification and transfer of liability, and can be reasonably assured of providing acceptable long-tem landscape performance including protecting environmental values (McKenna, 2002). In short, few mines globally reach our standard of sustainable mining - especially in the call to enhance the environment. This is urgently needed in closure and reclamation, which is arguably the greatest opportunity for mining companies to walk the talk and demonstrate that their sustainability commitment is more than empty words.

Successful reclamation can be measured as it supports the mine during operation, as it applies to landscape performance, and by its endpoint.

Successful reclamation:

- 'As measured during operations' means that progressive reclamation and certification occurs throughout the life of a mine, using an open and transparent decision-making process that includes regulators and all stakeholders (local groups and communities affected by decisions and who have an interest in the operation), in a way that attracts and keeps the trust between all three groups throughout the life of a mine so that reclamation supports the major business goals of the mining company.

- 'As shown through landscape performance' means that the reclaimed land meets agreed upon land uses, there is reasonable assurance that the land will continue to exhibit good performance and will continue to be an acceptable and useful part of the regional landscape and its ecosystems.

- 'As measured against an endpoint' means that transfer of liability for, and custodianship of, reclaimed land is turned over to a willing recipient (usually the state) in an orderly, timely, and economical manner and allows fulfilment of the 'temporary use of the land' covenant.

The ideal program would follow the following path:

- A comprehensive closure plan is completed prior to start up, is executed over the life of a mine and remains on schedule, on budget, and with no major changes or surprises. The closure plan is fully integrated with the ongoing operation.

- An effective stakeholder and regulatory consultation process starts before mining, continues beyond custodial transfer, and involves meaningful ongoing dialog with all interested parties.

- There is a steady level of progressive reclamation, including all aspects of reclamation such as resloping, cover soiling, revegetation, creeks and river establishment, monitoring and maintenance. Low variation in levels and types of annual activities allows a steady and experienced reclamation workforce and consistently level budgets.

- Land is certified progressively, and after a few start-up years, there are equal amounts of land being disturbed, reclaimed, and certified every year. The work, while still requiring innovation and creativity, becomes a routine part of the mine's annual operating cycle. At closure the last disturbed land is reclaimed and certified promptly. 
- Reclamation is indistinguishable from the operation, with large mining equipment handling much of the reclamation work as part of its normal operation.

- Research is carried out in advance of mining, or provides just-in-time answers for reclamation activities.

- Goals are few, achievable, practical, environmentally sound, and sufficient to ensure reasonable landscape performance. The goals of stakeholders, regulators, and miners are coincident and do not change with time.

- Any long term monitoring or maintenance is planned for and agreed to by all parties and executed in a timely and economic manner.

- Mechanisms are in place to allow timely and progressive custodial transfer of the land along with residual liability.

- The resulting landscape is useful and fits into (and supports) the local ecosystems and economy. Changes to the land, in terms of use or properties, are understood and accepted by all.

- The mine, stakeholders, and regulators earn and keep each other's trust throughout the life of the mine.

- All parties are accepting and proud of the accomplishments in creating a new landscape.

\section{Conclusions}

Most mining companies have publicly stated commitments to sustainability. Many produce an annual sustainability or corporate responsibility report. But for the most part, these efforts are little more than a repackaging of existing social and environmental activities, and crucially, separate from mine operations and corporate or line decision-making. Said simply, these commitments and reporting efforts are wellintentioned, but they are proportionally more public relations and communications devices than something of real substance that defines overall corporate performance. What is lacking is a roadmap to guide the achievement of sustainable mining now - a blueprint for corporate executives and mine managers to implement meaningful sustainable mining such that it becomes the new normal. A template, or conceptual frame of reference, is the industry's experience with safety and the efforts that have been made globally to weave a real culture of safety into day-to-day operations. So it needs to be with sustainability. Sustainable mining is needed to ensure future generations on earth enjoy the same opportunities that we were bequeathed from the generation that came before us, but it is about more than that. It is also about building companies that people are proud of; companies that endure; companies that provide good financial returns to shareholders and satisfaction for management; companies that are seen to be pillars of the communities in which they operate - and in the communities of interest that monitor and track these companies. In short, sustainable mining as we define it is not a 'nice to have'; it is smart business. It is our view that sustainable mining is the emergent outcome of doing the following seven things as excellently as possible: Engaging communities and earning trust; Exercising planning, decision making, and design with flair; executing promises operationally; empowering employees; efficiently managing resources; exceeding shareholder expectations; and Enhancing the environment.

\section{Acknowledgements}

We are grateful to the management and staff of BGC Engineering, who supported this idea and provided valuable feedback on earlier versions of the text. Equally, we acknowledge the management and staff of Teck Resources, in particular Robin Johnstone, for creating a pioneering external advisory panel experience (see SAPSM, 2010) that provided the authors with the seed of the idea that became Sustainable Mining Now. 


\section{References}

Cronon, W. (1995) Uncommon ground: toward reinventing nature, W.W. Norton \& Co., New York, 561 p.

McHarg, I, (1969) Design with Nature: New York, Wiley, 197 p.

McKenna, G.T. (2002) Sustainable mine reclamation and landscape engineering, PhD Thesis, University of Alberta, Edmonton, Canada, $661 \mathrm{p}$.

SAPSM (2010) Strategic Advisory Panel on Selenium Management. The Way Forward: A Strategic Plan for the Management of Selenium at Teck Coal Operations, viewed 3 August 2012, http://www.teck.com/Generic.aspx?PAGE=Teck Site/Responsibility Pages/Sustainability Pages/Environment Pages/. 
